\title{
A Comparison of Costoclavicular Block and Interscalene Block for Pain Relief after Arthroscopic Shoulder Surgery
}

\author{
Kamalakanta Pradhan ${ }^{1}$ Sarat Chandra Jayasingh ${ }^{2} \quad$ Sikata Nanda ${ }^{3} \quad$ Sidharth Sraban Routray ${ }^{1}$ \\ ${ }^{1}$ Department of Anesthesiology and Critical Care, SCB Medical \\ College Cuttack, Odisha, India \\ ${ }^{2}$ Department of Surgical Gastroenterology, SCB Medical College, \\ Cuttack, Odisha, India \\ Address for correspondence Sidharth Sraban Routray, MD, \\ Department of Anesthesiology and Critical Care, SCB Medical \\ College, Cuttack 753007, Odisha, India (e-mail: drsidharth74@ \\ gmail.com).
}

${ }^{3}$ Department of Community Medicine, SCB Medical College

Cuttack, Odisha, India

Int J Recent Surg Med Sci 2022;8:22-26.

DOI https://doi.org/

$10.1055 / \mathrm{s}-0041-1734210$

ISSN 2455-7420
Introduction Interscalene block (ISB) is commonly used for efficient pain relief after arthroscopic shoulder surgery. But, it is linked with a greater occurrence of unilateral diaphragmatic paralysis (UDP). This may add to patient dissatisfaction and also may not be tolerated well by patients having respiratory diseases. We have compared the efficacy of costoclavicular block (CCB) with ISB for postoperative analgesia in patients undergoing arthroscopic shoulder surgery.

Materials and Methods Fifty patients were divided into two groups of 25 each (ISB or CCB group). In total, $20 \mathrm{~mL}$ of $0.5 \%$ levobupivacaine along with $4 \mathrm{mg}$ of dexamethasone as adjuvant was used during both ultrasound-guided ISB and CCB. Numerical rating scale (NRS) scores for pain were assessed at $0,0.5,1,2,3,6,12$, and 24 hours in postoperative period. The mean onset time of block, time of first painkiller demand, total painkiller demand for 24 hours postoperatively, patient wellbeing, incidence of UDP, and any other complications were recorded.

Results NRS pain scores in both groups at $0,0.5,1,2,3,6,12$, and 24 hours were comparable. $(p>0.05)$ Mean onset time of block was earlier in ISB group contrary to CCB group $(p<0.05)$. There was higher occurrence of UDP in ISB group contrary to CCB group $(p<0.05)$. There was no notable variation regarding the time of first painkiller demand and total painkiller demand in the first 24 hours. Patients were more satisfied in CCB group contrary to ISB group.

Conclusion As CCB provided equivalent analgesia in postoperative period like ISB without any risk of UDP, it can be a better substitute to ISB for pain relief in arthroscopic shoulder surgery.

- shoulder surgery

- arthroscopy

(C) 2021. Medical and Surgical Update Society.

This is an open access article published by Thieme under the terms of the Creative Commons Attribution-NonDerivative-NonCommercial-License, permitting copying and reproduction so long as the original work is given appropriate credit. Contents may not be used for commercial purposes, or adapted, remixed, transformed or built upon. (https://creativecommons.org/licenses/by-nc-nd/4.0/).

Thieme Medical and Scientific Publishers Pvt. Ltd. A-12, 2nd Floor, Sector 2, Noida-201301 UP, India 


\section{Introduction}

Arthroscopic shoulder surgeries are minimally invasive procedures, which are usually associated with moderate to severe postoperative pain. This can produce serious aches and pains to the patients, leading to delayed recovery, rehabilitation, and discharge. ${ }^{1}$ Patients with pre-existing respiratory diseases pose a challenge for postoperative analgesia after shoulder surgery as interscalene block (ISB), commonly used block for shoulder surgery, can produce unilateral diaphragmatic paralysis (UDP). ISB was also associated with complications like arm weakness, Horner's syndrome, and hoarseness of voice. Whereas so many nerve blocks sparing diaphragm have been studied, no block has come close to provide equipotent analgesia to ISB without producing UDP. ${ }^{2}$ In a study by Wiegel et al, ${ }^{3}$ they concluded that analgesic efficacy of isolated suprascapular blocks was not so potent. Lee et $\mathrm{al}^{4}$ studied combined suprascapular and axillary nerve block which produced poor analgesia after arthroscopic surgery. Karmakar et $\mathrm{l}^{5}$ described the costoclavicular block (CCB) in which they earmarked the costoclavicular space (CCS) to block the brachial plexus. They opined that, three cords are densely packed and tightly clustered in CCS. So lower local anesthetic volume is needed for the block and also avoid the chance of pneumothorax and UDP. Garcia-Vitoria et $\mathrm{al}^{6}$ in their study opined that the CCS can act as a backward route to block supraclavicular brachial plexus which can avoid UDP. There were very few studies in literature comparing ISB with CCB for postoperative analgesia after arthroscopic shoulder surgeries. So in this study, we have compared CCB with ISB for pain relief after arthroscopic shoulder surgery.

\section{Materials and Methods}

We have conducted this randomized, prospective trial in a tertiary care hospital from January 2020 to January 2021 after obtaining Institutional Ethical Committee approval and written informed consent. Fifty patients of ASA I/II and aged 18 to 70years, posted for arthroscopic shoulder surgery were enrolled in our trial. Patients with pre-existing respiratory disease, coagulation abnormalities, infection at the site of block, liver or renal problems, pregnancy, hypersensitivity to local anesthetics, and prior surgery in the block site were excluded from the study. On arrival in operation theater, an 18-gauge intravenous (IV) cannula was put. Premedicant like IV midazolam $0.04 \mathrm{mg} / \mathrm{kg}$ and fentanyl $1 \mu \mathrm{g} / \mathrm{kg}$ were injected to all patients. Oxygen was supplemented at the rate of $5 \mathrm{~L} / \mathrm{min}$ and $\mathrm{SpO}_{2}$, pulse rate, noninvasive blood pressure, and ECG were monitored. For both blocks, GE Logiq F ultrasound with a high frequency (6-15 MHz) of $38 \mathrm{~mm}$ L6-12 linear probe was used. Using a computer-initiated sequence of random numbers all patients were randomly distributed into two groups, ISB $(n=25)$ and CCB $(n=25)$. The allocation outcomes were kept consecutively in a nontransparent and sealed cover, which was opened by the investigator before executing the blocks. ISB was given as narrated by Spence et al. ${ }^{7}$ The transducer was put at the level of the cricoid cartilage on the lateral side of neck. Three hypoechoic structural images, representing the roots and trunks of the brachial plexus were visualized. Using in-plane approach, the needle was guided from lateral-to-medial direction. When tip reaches below the prevertebral fascia and lies between the two superficial hypoechoic images, $20 \mathrm{~mL}$ of levobupivacaine $0.5 \%$ with $4 \mathrm{mg}$ dexamethasone was injected. CCB was given as described by Karmakar et al. ${ }^{5}$ The transducer was initially put over the middle one-third of the clavicle. Then it was gradually shifted below the lower margin and placed in medial infraclavicular fossa. Axillary artery was recognized below the subclavius muscle and lateral to the axillary artery, three brachial plexus cords were identified. In-plane approach was used, and the needle was guided till the tip reaches the middle of three cords where $20 \mathrm{~mL}$ of levobupivacaine $0.5 \%$ with $4 \mathrm{mg}$ dexamethasone was injected. All the blocks were given by experienced anesthesiologist. After the performance of the blocks, blocks were evaluated at every 5 minutes until 30 minutes. Sensation was assessed over the clavicle area for supraclavicular nerve and the lateral part of the deltoid for axillary nerve. For sensory block, every area was classified as per a three-point scale utilizing a cold test ${ }^{8}$ : failed block-0, analgesia-1, anesthesia-2. Motor block was assessed by various movements of shoulder like external rotation for suprascapular nerve and abduction for axillary nerve using a three-point scale: failed block-0, paresis-1, paralysis-2. Block was perfect, if the combined sensory-motor score was $\geq 6$ out of maximum score 8,30 minutes after block. ${ }^{8}$

UDP was assessed by the anesthesiologist blinded to the study group at 30 minutes after the blocks. Onset time of block was interpreted as the time needed for combined score of 6 to be achieved. After assessment of all the blocks, patients were administered general anesthesia using IV fentanyl (1 $\mu \mathrm{g} / \mathrm{kg})$, propofol (2 $\mathrm{mg} / \mathrm{kg})$, and vecuronium $(0.1 \mathrm{mg} / \mathrm{kg})$. After surgery is over, patients were shifted to post anesthesia care unit (PACU) after extubation. In PACU, another anesthesiologist assessed pain on rest at $0.5,1,2,3$, 6,12 , and 24 hours. Numerical rating scale (NRS) was used to assess pain. (no pain-0, worst imaginable pain-10). ${ }^{9}$ If NRS score was $>4$, paracetamol $15 \mathrm{mg} / \mathrm{kg}$ was given IV. Same anesthesiologist evaluated UDP at 30 minutes after arrival in the PACU using ultrasound. Mean performance time, complete blocks at 30 minutes, mean onset time, time of first painkiller demand, and total painkiller demand were recorded. The incidence of other complications like hoarseness and Horner syndrome was recorded. Patient wellbeing was assessed on questionnaire method with a four-point measurement (excellent, good, fair, poor). NRS score variation between ISB and CCB group of less than 1.3 points studied at different time interval was taken as significant. Established on an earlier trial, ${ }^{10}$ the difference in NRS score was presumed to be 1.5 between the two groups within first 24 hours. So, taking the $\alpha$ as 0.05 and power as 0.90 , the least needed sample size was calculated to be 22 for each group. Sample size was increased to 25 patients per group, anticipating loss of $10 \%$ patients to follow-up. Chi-square test was used for categorical data. For the numerical data, Student $t$-test or ANOVA was used. $p$-Values $<0.05$ was taken as statistically significant. 


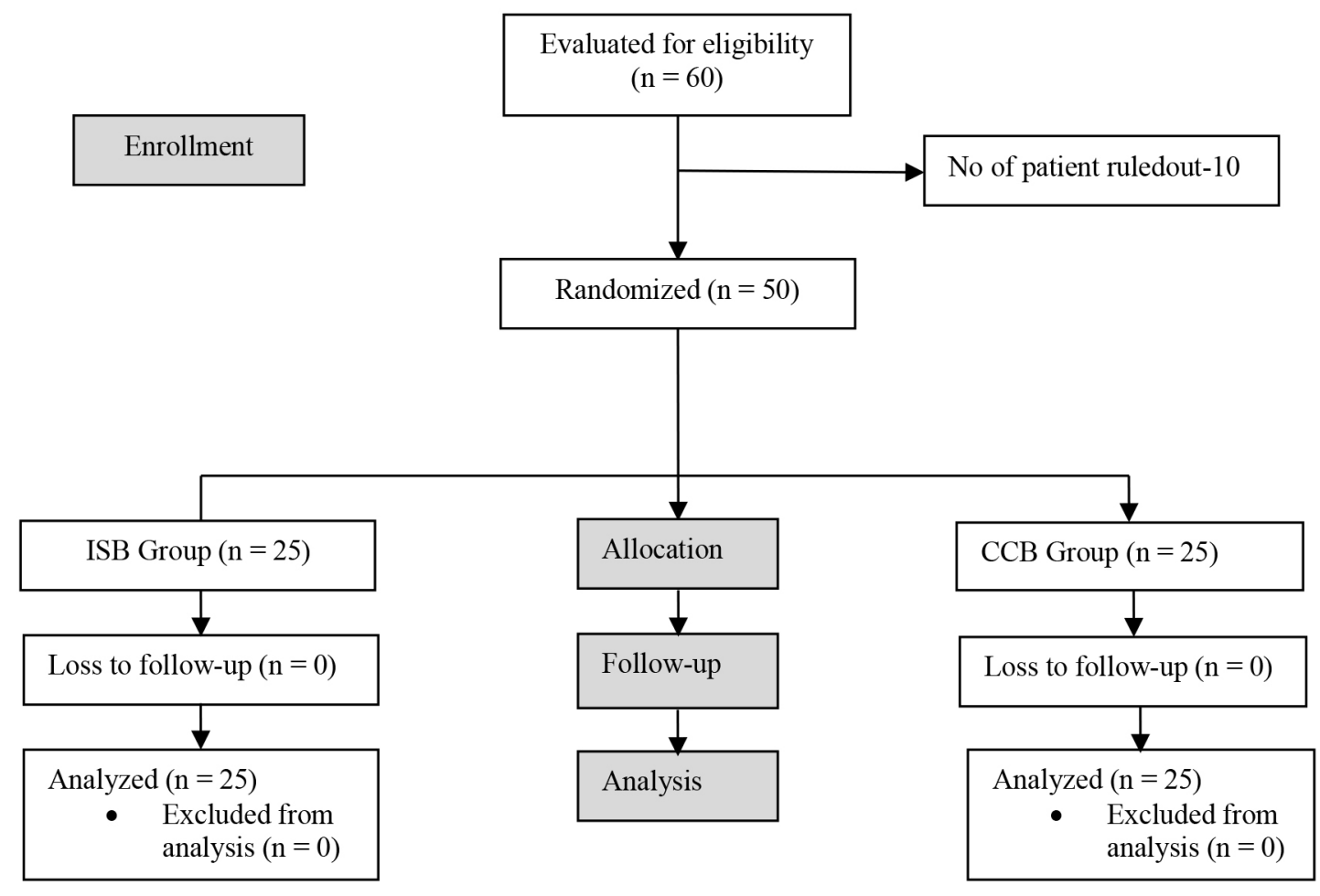

Fig. 1 CONSORT diagram showing patient flow.

Table 1 Patient demographic profile, type, and duration of surgery

\begin{tabular}{|l|l|l|l|}
\hline Variables & $\begin{array}{l}\text { Group ISB } \\
(\boldsymbol{n}-\mathbf{2 5})\end{array}$ & $\begin{array}{l}\text { Group CCB } \\
(\boldsymbol{n} \text { - 25) }\end{array}$ & $\boldsymbol{p}$-Value \\
\hline Age in years & $\begin{array}{l}51.42 \pm \\
11.74\end{array}$ & $\begin{array}{l}52.85 \pm \\
11.94\end{array}$ & 0.231 \\
\hline Male /Female, $(n)$ & $20 / 5$ & $19 / 6$ & 0.354 \\
\hline BMI in $\left(\mathrm{kg} / \mathrm{m}^{2}\right)$ & $25.12 \pm 2.55$ & $15.86 \pm 3.12$ & 0.251 \\
\hline ASA status-I/II $(n)$ & $16 / 9$ & $18 / 7$ & 0.364 \\
\hline $\begin{array}{l}\text { Pre op NRS score } \\
\text { at rest }\end{array}$ & $3.31 \pm 1.05$ & $3.54 \pm 1.32$ & 0.540 \\
\hline $\begin{array}{l}\text { Type of surgery }(n) \\
\text { Rotator cuff repair }\end{array}$ & 12 & 10 & 0.156 \\
\hline Acromioplasty $(n)$ & 8 & 11 & 0.195 \\
\hline Bankart repair $(n)$ & 5 & 4 & 0.207 \\
\hline $\begin{array}{l}\text { Duration of surgery } \\
\text { (min) }\end{array}$ & $110.55 \pm$ & $\begin{array}{l}114.34 \pm \\
24.14\end{array}$ & 0.412 \\
\hline
\end{tabular}

Abbreviations: CCB, costoclavicular block; ISB, interscalene block.

\section{Results}

Sixty participants were evaluated for eligibility and ten of them were ruled out as they did not meet the inclusion criteria. So, 50 patients were enrolled for this study (-Fig. 1). There were no statistically remarkable variation in both groups (A and B) regarding demographic parameters, ASA
Table 2 Numeric rating scale scores at rest at various time interval

\begin{tabular}{|l|l|l|l|}
\hline $\begin{array}{l}\text { Time } \\
\text { interval }\end{array}$ & $\begin{array}{l}\text { Group ISB } \\
(\boldsymbol{n}-\mathbf{2 5})\end{array}$ & $\begin{array}{l}\text { Group CCB } \\
(\boldsymbol{n}-\mathbf{2 5})\end{array}$ & $p$-Value \\
\hline 0 min & $1.75 \pm 2.14$ & $1.6 \pm 2.12$ & 0.146 \\
\hline 30th min & $1.42 \pm 1.66$ & $1.32 \pm 1.74$ & 0.172 \\
\hline 1st h & $1.58 \pm 1.43$ & $1.92 \pm 1.78$ & 0.184 \\
\hline 2nd h & $1.75 \pm 1.73$ & $1.25 \pm 1.14$ & 0.158 \\
\hline 3rd h & $1.8 \pm 1.25$ & $2.24 \pm 1.48$ & 0.193 \\
\hline 6th h & $1.6 \pm 1.48$ & $2.83 \pm 0.93$ & 0.256 \\
\hline 12th h & $2.8 \pm 1.4$ & $2.23 \pm 1.81$ & 0.167 \\
\hline 24th h & $2.95 \pm 0.93$ & $2.89 \pm 0.83$ & 0.178 \\
\hline
\end{tabular}

Abbreviations: CCB, costoclavicular block; ISB, interscalene block.

status, preoperative NRS score, type of surgery, and duration of surgery (-Table $\mathbf{1}$ ).

NRS scores were comparable in both groups at $0,0.5,1,2$, $3,6,12$, and 24 hours postoperatively $(p>0.05)$ (-Table 2 ). Mean onset time of block was earlier and patient wellbeing was better in CCB group compared with ISB block $(p<0.05)$. Both groups were comparable with regard to mean performance time, perfect blocks at 30 minutes, time of first painkiller demand, and total painkiller demand $(p>0.05)$ (-Table 3). Incidence of UDP 30 minutes after the block and in the PACU was greater in ISB group contrary to CCB group $(p$ $<0.05$ ). Regarding other complications like Horner syndrome and hoarseness, both groups were comparable ( - Table 4 ). 
Table 3 Block parameters and pain killer requirement

\begin{tabular}{|l|l|l|l|}
\hline Parameters & Group ISB $(\boldsymbol{n}-\mathbf{2 5})$ & Group CCB $(\boldsymbol{n}-\mathbf{2 5})$ & $\boldsymbol{p}$-Value \\
\hline Performance time of block (min) & $8.5 \pm 2.9$ & $8.1 \pm 3.9$ & $>0.05$ \\
\hline Onset time of block (min) & 15.784 .50 & 20.423 .74 & $<0.05$ \\
\hline Perfect block at 30 min ( $[\%])$ & $25(100 \%)$ & $25(100 \%)$ & $>0.05$ \\
\hline Time of first painkiller demand (h) & $6.8 \pm 1.5$ & $6.4 \pm 1.8$ & $>0.05$ \\
\hline Total painkiller demand $(g)$ & $2.4 \pm 0.7$ & $2.6 \pm 0.6$ & $>0.05$ \\
\hline Patient wellbeing at 24 h $(n)$ (Excellent: good: fair: poor) & $8: 15: 2: 0$ & $20: 4: 1: 0$ & $<0.05$ \\
\hline
\end{tabular}

Abbreviations: CCB, costoclavicular block; ISB, interscalene block.

Table 4 Complications of ISB and CCB

\begin{tabular}{|l|l|l|l|}
\hline Parameters & Group ISB $(\boldsymbol{n}-25)$ & Group CCB $(\boldsymbol{n}-\mathbf{2 5})$ & $\boldsymbol{p}$-Value \\
\hline $\begin{array}{l}\text { Unilateral diaphragmatic paralysis after } 30 \text { min of } \\
\text { block }(n[\%])\end{array}$ & $20(80 \%)$ & 0 & $<0.05$ \\
\hline Unilateral diaphragmatic paralysis in PACU) $(n[\%])$ & $20(80 \%)$ & 0 & $<0.05$ \\
\hline Horner syndrome $(n[\%])$ & $1(4 \%)$ & 0 & $>0.05$ \\
\hline Hoarseness $(n[\%])$ & $2(8 \%)$ & $2(8 \%)$ & $>0.05$ \\
\hline
\end{tabular}

Abbreviations: CCB, costoclavicular block; ISB, interscalene block; PACU, post anesthesia care unit.

\section{Discussion}

ISB is the benchmark block commonly used for postoperative pain management after any shoulder surgery. ISB decreases the pain scores for minimum 6 to 8 hours and reduces opioid requirement in postoperative 24 hours. ${ }^{11}$ Efficacy of ISB in shoulder surgery has been well studied by Dhir et al, ${ }^{12}$ Pitombo et al, $^{13}$ and Neuts et al. $^{14}$ But there were concerns regarding phrenic nerve paralysis and UDP in ISB which can produce transient and long-term respiratory complications. ${ }^{5}$ Many different nerve blocks for shoulder analgesia which spare the phrenic nerve have been studied by Tran et al. ${ }^{15}$ They opined that, no block provided surgical anesthesia without phrenic nerve paralysis. Few cadaveric and therapeutic trials have opined that, CCB may be utilized as a substitute to ISB for postoperative pain relief after shoulder surgery. Mistry et al ${ }^{16}$ has given $15 \mathrm{~mL}$ of local anesthetics in bilateral CCB and found good analgesia without phrenic nerve paralysis. Also, Koyyalamudi et al ${ }^{17}$ in a human cadaveric trial approved this. In his study, $20 \mathrm{~mL}$ of $0.1 \%$ methylene blue was injected to CCS and the dye was found spreading toward craniad part of brachial plexus. Whole of the trunks and cords of the brachial plexus was stained, but phrenic nerve was not stained. So, they opined that, local anesthetics injected to CCS may spare phrenic nerve. But incidence of phrenic nerve paralysis in CCB in different studies varied as different volume of drug was used in those studies. Sivashanmugam et $\mathrm{al}^{18}$ in their study concluded that, the incidence of unilateral phrenic nerve paralysis was nil with $20 \mathrm{~mL}$ of drug and was maximum $8.9 \%$ when $35 \mathrm{~mL}$ of drug used in CCB in different studies. In our study, we found that NRS scores were comparable in both ISB and CCB groups at $0,0.5,1,2,3,6,12$, and 24 hours postoperatively. Mean onset time of block was earlier and patient well-being was better in CCB group contrary to ISB group. Incidence of UDP, 30 minutes after the block and in the PACU was greater in ISB group contrary to CCB group. $(p<0.05)$. This was in agreement with a study by Aliste et al. ${ }^{10}$ They have compared the efficacy of CCB with ISB for pain relief and any complications after arthroscopic shoulder surgery. They concluded that, both ISB and CCB produced equivalent analgesia without any occurrence of phrenic nerve paralysis. They hypothesized that, from CCS local anesthetics spread cephalad, toward the brachial plexus roots while blocking the trunks and cords, thereby block the shoulder innervations sparing phrenic nerve. They have advocated for larger trial taking more number of patients to validate their findings. Spread of local anesthetics in interscalene groove in the direction of phrenic nerve or toward C3-C5 nerve roots is a possible mechanism of UDP after ISB. Leurcharusmee et $\mathrm{al}^{19}$ in their study opined that, on moving from ISB toward supraclavicular brachial plexus blocks, occurrence of UDP gradually decreases from $100 \%$ to as low as $67 \%$. On moving further below toward the CCS in the infraclavicular region, incidence of UDP further decreased. Aliste et $\mathrm{al}^{10}$ hypothesized that the CCB reliably anesthetize the lateral cord, posterior cord, supraclavicular brachial plexus, and the suprascapular nerve and termed it as a sweet spot. One of the dilemmas in CCB was that the ideal volume of local anesthetic was still not known. Sotthisopha et $\mathrm{al}^{20}$ in his study of CCB concluded that in $90 \%$ of CCB, the minimum required volume of local anesthetic (1.5\% lidocaine) is $34 \mathrm{~mL}$ for effective block. But in our study, we have used low volume $(20 \mathrm{~mL})$ of local anesthetic as suggested by Karmakar et al. ${ }^{5}$ With our aim to homogenize the local anesthesia volume in the two groups and to reduce incidence of UDP, we have used $20 \mathrm{~mL}$ of local anesthesia in our study. We have added dexamethasone ( $4 \mathrm{mg}$ ) as adjuvant to levobupivacaine to prolong the duration of action. Lastly CCB may be used an alternative to ISB as it was equally potent and spare the phrenic nerve but one of the limitations of our 
study was that the number of participants was low. So large scale studies are required to authenticate our findings.

\section{Conclusion}

Our study concludes that newer regional block like CCB prolongs the duration of analgesia and produces identical postoperative pain relief like ISB but unlike interscalene block it does not produce UDP. So CCB can be used as a substitute for interscalene block for effective postoperative pain relief after arthroscopic shoulder surgery specifically in patients having respiratory diseases.

\section{Conflict of Interest}

None declared.

\section{References}

1 Auyong DB, Yuan SC, Choi DS, Pahang JA, Slee AE, Hanson NA. A double-blind randomized comparison of continuous interscalene, supraclavicular, and suprascapular blocks for total shoulder arthroplasty. Reg Anesth Pain Med 2017;42(3):302-309

2 Tran DQ, Elgueta MF, Aliste J, Finlayson RJ. Diaphragm-sparing nerve blocks for shoulder surgery. Reg Anesth Pain Med 2017;42(1):32-38

3 Wiegel M, Moriggl B, Schwarzkopf P, Petroff D, Reske AW. Anterior suprascapular nerve block versus interscalene brachial plexus block for shoulder surgery in the outpatient setting: a randomized controlled patient- and assessor-blinded trial. Reg Anesth Pain Med 2017;42(3):310-318

4 Lee JJ, Kim DY, Hwang JT, et al. Effect of ultrasonographically guided axillary nerve block combined with suprascapular nerve block in arthroscopic rotator cuff repair: a randomized controlled trial. Arthroscopy 2014;30(8):906-914

5 Karmakar MK, Sala-Blanch X, Songthamwat B, Tsui BC. Benefits of the costoclavicular space for ultrasound-guided infraclavicular brachial plexus block: description of a costoclavicular approach. Reg Anesth Pain Med 2015;40(3):287-288

6 García-Vitoria C, Vizuete J, López Navarro AM, Bosch M. Costoclavicular space: a reliable gate for continuous regional anesthesia catheter insertion. Anesthesiology 2017;127(4):712

7 Spence BC, Beach ML, Gallagher JD, Sites BD. Ultrasound-guided interscalene blocks: understanding where to inject the local anaesthetic. Anaesthesia 2011;66(6):509-514

8 Aliste J, Bravo D, Fernández D, Layera S, Finlayson RJ, Tran DQ. a randomized comparison between interscalene and small-volume supraclavicular blocks for arthroscopic shoulder surgery. Reg Anesth Pain Med 2018;43(6):590-595
9 Aliste J, Bravo D, Finlayson RJ, Tran DQ. A randomized comparison between interscalene and combined infraclavicular-suprascapular blocks for arthroscopic shoulder surgery. Can J Anaesth 2018;65(3):280-287

10 Aliste J, Bravo D, Layera S, et al. Randomized comparison between interscalene and costoclavicular blocks for arthroscopic shoulder surgery. Reg Anesth Pain Med 2019;44:472-477

11 Singelyn FJ, Lhotel L, Fabre B. Pain relief after arthroscopic shoulder surgery: a comparison of intraarticular analgesia, suprascapular nerve block, and interscalene brachial plexus block. Anesth Analg 2004;99(2):589-592

12 Dhir S, Sondekoppam RV, Sharma R, Ganapathy S, Athwal GS. A comparison of combined suprascapular and axillary nerve blocks to interscalene nerve block for analgesia in arthroscopic shoulder surgery: an equivalence study. Reg Anesth Pain Med 2016;41(5):564-571

13 Pitombo PF, Meira Barros R, Matos MA, Pinheiro Módolo NS. Selective suprascapular and axillary nerve block provides adequate analgesia and minimal motor block. Comparison with interscalene block. Braz J Anesthesiol 2013;63(1):45-51

14 Neuts A, Stessel B, Wouters PF, et al. Selective suprascapular and axillary nerve block versus interscalene plexus block for pain control after arthroscopic shoulder surgery: a noninferiority randomized parallel-controlled clinical trial. Reg Anesth Pain Med 2018;43(7):738-744

15 Tran DQ, Layera S, Bravo D, Cristi-Sanchéz I, Bermudéz L, Aliste J. Diaphragm-sparing nerve blocks for shoulder surgery, revisited. Reg Anesth Pain Med 2020;46:288-289

16 Mistry T, Balavenkatasubhramanian J, Natarajan V, Kuppusamy E. Ultrasound-guided bilateral costoclavicular brachial plexus blocks for single-stage bilateral upper limb surgeries: abstain or indulge. J Anaesthesiol Clin Pharmacol 2019;35(4):556-557

17 Koyyalamudi V, Langley NR, Harbell MW, Kraus MB, Craner RC, Seamans DP. Evaluating the spread of costoclavicular brachial plexus block: an anatomical study. Reg Anesth Pain Med 2021;46(1):31-34

18 Sivashanmugam T, Maurya I, Kumar N, Karmakar MK. Ipsilateral hemidiaphragmatic paresis after a supraclavicular and costoclavicular brachial plexus block: a randomised observer blinded study. Eur J Anaesthesiol 2019;36(10):787-795

19 Leurcharusmee P, Elgueta MF, Tiyaprasertkul W, et al. A randomized comparison between costoclavicular and paracoracoid ultrasound-guided infraclavicular block for upper limb surgery. Can J Anaesth 2017;64(6):617-625

20 Sotthisopha T, Elgueta MF, Samerchua A, et al. Minimum effective volume of lidocaine for ultrasound-guided costoclavicular block. Reg Anesth Pain Med 2017;42(5):571-574 